\title{
TENDENCIAS Y OPORTUNIDADES DE DESARROLLO TURÍSTICO EN LA COSTA TROPICAL DE GRANADA: LA VISIÓN DE LOS MUNICIPIOS
}

\author{
Jesús Alberto Espinosa Arias* \\ Universidad de Guadalajara. México \\ Francisco de Asís Rodríguez Martínez** \\ Universidad de Granada
}

\section{RESUMEN}

El artículo presenta la situación del turismo litoral español, el desarrollo del turismo en la Costa de Granada y su evolución, como uno de los espacios litorales del país con poco desarrollo del turismo. Por medio de entrevistas se presenta la visión de los alcaldes. Se reconoce la potencialidad turística de la zona y la importancia de la Mancomunidad de Municipios como ente para la planeación del desarrollo turístico; sin embargo, se percibe una ausencia de liderazgo y visión común. Se vislumbra a la Mancomunidad como la instancia que debe impulsar el desarrollo en la costa de Granada.

Palabras clave: Turismo sostenible, actores locales, mancomunidad de municipios, complementariedad territorial, costa tropical de Granada.

\section{Trends and opportunities of tourism development in tropical coast Granada: The vision of the municipalities}

\section{ABSTRACT}

This article presents the situation of Spanish coastal tourism, its evolution and development at Coast of Granada as one of the country's coastal areas with incipient tourism development.

Recibido: 24 de septiembre de 2013

Devuelto para su revisión: 4 de marzo de 2014

Aceptado: 3 de noviembre de 2014

* Departamento de Desarrollo Regional. Centro Universitario del Sur. Universidad de Guadalajara. Av. Enrique Arreola Silva, nº 883, Col. Centro. C.P. 49000. CIUDAD GUZMÁN, Jalisco (México). E-mail: jesuse@ cusur.udg.mx

** Departamento de Análisis Geográfico Regional y Geografía Física. Facultad de Filosofía y Letras. Universidad de Granada. Campus de Cartuja, s/n. 18071 GRANADA (España).E-mail: fcorodri@ugr.es 
Interviews were conducted in order to present the visions of local mayors. Tourist potential and relevance of the Association of Municipalities as an entity for the planning tourism development is recognized, however, a lack of leadership and common vision is perceived. This Association of Municipalities could act as a leader to promote the development on the coast of Granada.

Key words: Sustainable tourism, local actors, association of municipalities, territorial complementarity, tropical coast of Granada.

\section{INTRODUCCIÓN}

Hablar de turismo en España, es hablar de uno de los países con liderazgo mundial en esta actividad. El presente trabajo se divide en dos secciones: en la primera parte se plantea un breve análisis de la situación del turismo español, así como de los retos que se tienen a futuro. La segunda parte se centra en el desarrollo del turismo en la costa de Granada como uno de los espacios litorales poco desarrollados para el turismo, por lo que se establece la pregunta ¿por qué la costa de Granada no se ha desarrollado turísticamente?

Para abordar esta pregunta se ha planteado conocer la opinión de los 17 alcaldes de los municipios que integran la costa de Granada, esto se ha realizado por medio de entrevistas semiestructuradas a profundidad, con el fin de conocer desde su perspectiva la situación del turismo, las problemáticas y posibles soluciones. Las entrevistas se realizaron en el periodo comprendido entre marzo del 2012 a septiembre del 2013, excepto en tres municipios que se llevaron a cabo de mayo a septiembre del 2010. Entre los principales resultados destaca la importancia que representa para los alcaldes la Mancomunidad de Municipios de la Costa Tropical de Granada como el organismo de planeación para el desarrollo del turismo en la región, sin embargo existen diferencias en su integración, visión común y falta de liderazgo, pero se vislumbra que esta instancia que debe impulsar el desarrollo de nuevos liderazgos para en la costa de Granada.

\section{EL TURISMO LITORAL EN ESPAÑA}

El turismo litoral o de sol y playa en España, se caracteriza por ser masivo, de un uso intensivo de los recursos y marcada estacionalidad. Esto propicia una gran congestión en los meses estivales, saturación de playas, servicios insuficientes, dificultades en la movilidad, congestión de tránsito, contaminación acústica y servicios de baja calidad por término medio.

Sin embargo el turismo de litoral seguirá siendo el predominante en España. Como afirma Anton Clavé (2004: 316), el turismo en las costas españolas mediterráneas seguirá siendo el factor de atracción más relevante para los mercados emisores que se dirigen a España. Solo tomando como base la infraestructura hotelera, de acuerdo a datos de la encuesta de ocupación en alojamientos turísticos (INE, 2011), durante el 2010, se registraron 267.1 millones de pernoctaciones en establecimientos hoteleros. 
Dentro de estos, las zonas turísticas con mayor número de pernoctaciones registraron el 59,5\% (159 millones), correspondieron a sitios litorales; principalmente de Baleares, Canarias y la Costa Mediterránea, lo que da una idea del peso que tiene el turismo litoral en el país.

Una de las preocupaciones en los destinos turísticos litorales españoles, es la que se refiere a la disminución del número de días de estancia y del gasto medio, realizado por los turistas; Esto puede deberse a varias circunstancias entre las principales se encuentran:

1) La motivación del turista: quien ha cambiado sus hábitos de viaje, ha evolucionado de comprar paquetes estandarizados y básicos, a ser él quien marca la pauta, sobre lo que quiere, cómo lo quiere y cuándo lo quiere. Ahora el turista ha adquirido mayor experiencia, está mejor informado, se encuentra mejor preparado, exige mejores servicios y una relación calidad-precio justa, con una atención personalizada y una oferta más diversificada, en un entorno donde exista un respeto por los recursos naturales. Si las motivaciones han cambiado, los comportamientos también. Por otra parte, la fragmentación de las vacaciones ha provocado que se realicen viajes más cortos. Así, se ha pasado de una lógica de vender servicios al turista, a una lógica de vender experiencias que sean únicas e irrepetibles.

2) Las tecnologías de la información y comunicación. Las nuevas tecnologías informáticas han facilitado el cambio de motivación del turista. Por medio del internet se tiene acceso a una gran cantidad de información, que permite tener un primer acercamiento antes de tomar la decisión del viaje (Choi, 2007). Según el Instituto de Estudios Turísticos (2012), de los turistas que visitaron España durante el 2011, el $61 \%$, uso internet, el 69\% realizó una consulta referente a transporte, alojamiento o actividades y el $51 \%$ concretó la compra por esta vía. Está última estadística seguirá en aumento conforme más negocios acepten este sistema y se den más facilidades de acceso a formas de pago electrónico.

3) Un modelo litoral basado en atender las necesidades primarias del turista: con la infraestructura básica y poco diversificada, en el que se ha apostado por la intensa urbanización del espacio costero y del crecimiento inmobiliario es cuestionado por varios autores que dan cuenta de ello (Santos Pavón y Fernández Tabales, 2010).Incluso se han implementado términos como «urbanismo turístico» (Obiol Menero, 2011), o el de «turismo inmobiliario», con los cuales se definen a los lugares turísticos en donde el objetivo principal es el desarrollo inmobiliario teniendo como pantalla el turismo para desarrollar la segunda residencia, llamado más comúnmente «turismo residencial». Requejo Liberal (2008), afirma que en el caso de los extranjeros el nombre correcto debería ser «inmigrantes climáticos», debido a que son personas cuya principal motivación de estancia es el clima, por lo que siguen manteniendo su idioma y sus costumbres, sin tener interés por la cultura local. Sin embargo pese a los diferentes estudios sobre la pérdida de competitividad y los fuertes impactos ambientales que fomenta la segunda residencia, aún se sigue insistiendo en su desarrollo. Existen datos contundentes, 
como el del número de pernoctaciones de un establecimiento reglado genera con 144 noches respecto al de una segunda residencia con 48 noches, o el gasto medio que un turista en segunda residencia realiza de $33.37 €$, mientras que el turista que se aloja en un establecimiento reglado fue del 87.12€ (EXCELTUR, 2005); sin embargo, la visión de la obtención de ingresos a corto plazo sigue primando.

4) Impactos ambientales. La franja del litoral español cada día se va urbanizando en aras del desarrollo turístico; del año 1987 al 2000 se ha dado un incremento de la superficie artificial del 29,5\%, este ha ocurrido principalmente en las costas mediterráneas, y en las grandes y medianas ciudades (Observatorio de la sostenibilidad en España, 2006). Sin embargo, el impacto más fuerte y preocupante es que el 34,21\% del primer kilómetro de costa se encuentra urbanizado. Ojeda Zújar y Villar Lama (2006:86) realizaron un estudio sobre la evolución del suelo urbano/alterado en el litoral de Andalucía entre el periodo 1998-2002 $\mathrm{y}$ encontraron que en todo el litoral andaluz, la superficie de los primeros 500 $\mathrm{m}$ de línea de playa son los que más se han urbanizado, presentando diferentes grados, con la provincia de Málaga a la cabeza (60\%) y a Huelva con menos del $15 \%$. Los autores llegaron a la siguiente conclusión «la consagración del ladrillo y del asfalto se está haciendo a unos ritmos que raramente pueden asegurar la rentabilidad ambiental, económica y social, por ende territorial de este modelo a largo plazo». Estos datos son un llamado de alerta sobre el tipo de desarrollo que se ha realizado en el litoral español que está impactando fuertemente el desarrollo del turismo. Por otra parte, Greenpeace (2010), ha denunciado que el $59 \%$ del litoral de Andalucía se encuentra urbanizado. Estos impactos conllevan un deterioro de los recursos naturales y del paisaje. La Ley 02/2013, de 29 de mayo, de protección y uso sostenible del litoral (ley de costas), tendrá un efecto negativo y se vaticina que propiciará la construcción del poco espacio litoral que aún permanece intacto en el mediterráneo.

5) La competencia de destinos emergentes: la aparición de nuevos destinos que presentan ventajas medioambientales, paisajísticas y de precio, ponen en desventaja al litoral español. Países como Croacia, Túnez, Marruecos, Egipto o Turquía, están haciendo competencia enfocando su oferta hacia sol y playa con un coste más bajo. También se puede considerar en este apartado al Caribe con países como Cuba, República Dominicana, Puerto Rico y México, entre otros. Por otro lado, la inestabilidad recurrente y los conflictos sociales que existen en los países de competencia directa, como son Egipto, Grecia, Turquía y el norte de África, han sido favorables para que se mantenga la cuota de turistas que arriban al país cada año, ya que España es visto como un país en donde la seguridad es sinónimo de tranquilad para el turista.

Ante esta situación varios expertos en el estudio del turismo español han presentado una serie de estrategias y recomendaciones que apuntan hacia una adecuada planeación y ordenación del territorio, el respeto por el medio ambiente, la recuperación y restauración de los espacios naturales, la mejora y calidad de los servicios, la diversificación de la oferta entre otras que permita mejorar el posicionamiento del turismo español, basado 
en la sostenibilidad, el desarrollo local y la gobernanza (Pulido Fernández, 2011; Pirelli del Amo, 2011; Vera Rebollo, López Palomeque, Marchena y Anton Clavé, 2011; Santos Pavón, 2010).

Algo en lo que existe consenso, es en el hecho de que hay tantos modelos turísticos, como destinos existentes, debido a que cada uno presenta características particulares que lo distinguen de los demás, por lo que deben existir un mínimo de líneas estratégicas para caracterizar el modelo turístico español (Tabla 1). La Tabla que se presenta a continuación está basada principalmente en lo propuesto por Pulido Fernández (2011), presenta una propuesta basada en la sostenibilidad y sus dimensiones (económica, ambiental, social e institucional): 1) Dentro de la dimensión económica se propone principalmente nuevas herramientas y modelos de gestión de los destinos; prescindir de la sobrecapacidad de alojamiento, especialmente en el litoral; una política de rehabilitación de los destinos turísticos orientada a la rehabilitación de lo ya existente, con el fin de no consumir más suelo; plantear soluciones de financiamiento a los municipios turísticos para evitar que la venta de suelo se convierta en el principal ingreso; reorientar el papel de las comunidades autónomas en la promoción y gestión de la actividad turística. 2) En la dimensión ambiental se propone establecer objetivos al margen del crecimiento; romper con la instrumentalización del turismo para justificar una dinámica de producción inmobiliaria; internalizar los costes ambientales y sociales de producción y consumo turístico; incorporar una actitud proactiva hacia la gestión de los efectos del cambio climático como sector estratégico del turismo; establecer un sistema de accesibilidad y movilidad eficiente y sostenible, principalmente dentro de los destinos que permita desmotivar la utilización del automóvil. 3) En la dimensión social se formula potenciar el factor humano como parte fundamental del sector turístico; atender los intereses de las diferentes partes afectadas por el desarrollo turístico de los destinos; atender los fenómenos relacionados con el turismo de excesos que desprestigian al turismo español. 4) En lo referente a la dimensión institucional, las administraciones públicas están obligadas a asumir el liderazgo del cambio apoyándose en modelos de verdadera gobernanza y creando órganos de coordinación operativos; establecer nuevos esquemas jurídicos que propicien una mayor agilidad en las gestiones; implementar un centro de generación del conocimiento donde se tomen las experiencias de éxito y se generen nuevas formas de gestión, comercialización y distribución; desarrollar un sistema integral de información turística, que aproveche las nuevas tecnologías para establecer las nuevas formas de gestión (horizontal y vertical), los modelos de gobernanza, los órganos de coordinación operativa, la generación de los nuevos conocimientos en el área y que dé soporte para investigaciones, gestiones (redes, portales, páginas web) y el desarrollo de nuevas aplicaciones a la actividad turística.

\section{EL TURISMO EN LA COSTA TROPICAL DE GRANADA}

La costa tropical de Granada la integran 17 municipios con una superficie de 787 $\mathrm{km}^{2}$, que corresponden al 6,23\% del total de la provincia, con una población de 128.029 habitantes -el 13,84\% de la provincia- (Figura 1). De estos municipios, nueve son estrictamente costeros, seis de interior, aunque en el marco del «litoral topográfico» y los 
Tabla 1

PROPUESTA DEL NUEVO MODELO DE TURISMO EN ESPAÑA

\begin{tabular}{|c|c|c|c|}
\hline $\begin{array}{l}\text { DIMENSIÓN } \\
\text { ECONÓMICA }\end{array}$ & $\begin{array}{l}\text { DIMENSIÓN } \\
\text { AMBIENTAL }\end{array}$ & $\begin{array}{l}\text { DIMENSIÓN } \\
\text { SOCIAL }\end{array}$ & $\begin{array}{c}\text { DIMENSIÓN } \\
\text { INSTITUCIONAL }\end{array}$ \\
\hline $\begin{array}{l}\text { Desarrollar nuevas } \\
\text { herramientas y modelos } \\
\text { de gestión de los } \\
\text { destinos que garanticen } \\
\text { un mejor control de } \\
\text { estos. }\end{array}$ & $\begin{array}{l}\text { Superar el carácter } \\
\text { excluyente de } \\
\text { la orientación } \\
\text { ambientalista y } \\
\text { desarrollar verdaderas } \\
\text { estrategias de } \\
\text { sostenibilidad. }\end{array}$ & $\begin{array}{l}\text { Orientar los esfuerzos } \\
\text { a casar los intereses de } \\
\text { las diferentes partes } \\
\text { interesadas, o afectadas } \\
\text { por el desarrollo } \\
\text { turístico de cualquier } \\
\text { destino. }\end{array}$ & $\begin{array}{l}\text { Las administraciones } \\
\text { públicas deben asumir } \\
\text { el liderazgo que } \\
\text { requiere el cambio de } \\
\text { modelo. }\end{array}$ \\
\hline $\begin{array}{l}\text { Prescindir de la } \\
\text { sobrecapacidad } \\
\text { de alojamiento, } \\
\text { especialmente en el } \\
\text { litoral. }\end{array}$ & $\begin{array}{l}\text { Establecer objetivos al } \\
\text { margen del crecimiento }\end{array}$ & $\begin{array}{l}\text { Atajar fenómenos } \\
\text { relacionados con el } \\
\text { turismo de excesos. }\end{array}$ & $\begin{array}{l}\text { Introducir modelos de } \\
\text { verdadera gobernanza. }\end{array}$ \\
\hline $\begin{array}{l}\text { Mejorar la eficiencia de } \\
\text { la gestión pública del } \\
\text { turismo. }\end{array}$ & $\begin{array}{l}\text { Hacer un esfuerzo por } \\
\text { internalizar los costes } \\
\text { ambientales y sociales } \\
\text { de la producción y el } \\
\text { consumo turístico. }\end{array}$ & $\begin{array}{l}\text { Potenciar el factor } \\
\text { humano }\end{array}$ & $\begin{array}{l}\text { Generar órganos } \\
\text { de coordinación } \\
\text { administrativa } \\
\text { realmente operativos. }\end{array}$ \\
\hline $\begin{array}{l}\text { Reorientar el papel } \\
\text { de las comunidades } \\
\text { autónomas en la } \\
\text { promoción y gestión de } \\
\text { la actividad turística. }\end{array}$ & $\begin{array}{l}\text { Romper con la peligrosa } \\
\text { instrumentalización } \\
\text { del turismo para } \\
\text { justificar una dinámica } \\
\text { de producción } \\
\text { inmobiliaria. }\end{array}$ & & $\begin{array}{l}\text { Introducir nuevos } \\
\text { esquemas jurídicos. }\end{array}$ \\
\hline $\begin{array}{l}\text { Plantear soluciones } \\
\text { a las dificultades } \\
\text { financieras de los } \\
\text { municipios españoles, } \\
\text { especialmente a los } \\
\text { turísticos. }\end{array}$ & $\begin{array}{l}\text { Incorporar una actitud } \\
\text { proactiva hacia la } \\
\text { gestión de los efectos } \\
\text { del cambio climático } \\
\text { como un sector } \\
\text { estratégico del turismo } \\
\text { español. }\end{array}$ & & $\begin{array}{l}\text { Centro de Generación } \\
\text { de Conocimiento. }\end{array}$ \\
\hline \multirow[t]{2}{*}{$\begin{array}{l}\text { Política integral de } \\
\text { rehabilitación de los } \\
\text { destinos turísticos. }\end{array}$} & $\begin{array}{l}\text { Asumir el liderazgo } \\
\text { europeo en la defensa } \\
\text { de la aplicación } \\
\text { racional de las medidas } \\
\text { ambientales que afecten } \\
\text { al turismo } \\
\end{array}$ & & $\begin{array}{l}\text { Sistema Integral de } \\
\text { Información Turística }\end{array}$ \\
\hline & $\begin{array}{l}\text { Sistema de } \\
\text { accesibilidad y } \\
\text { movilidad eficiente y } \\
\text { sostenible }\end{array}$ & & \\
\hline
\end{tabular}

Fuente: Pulido Fernández (2011), Pirelli del Amo (2011), Vera Rebollo, et al (2011), elaboración propia. 


\section{Figura 1 \\ LOCALIZACIÓN DEL ÁREA DE ESTUDIO}

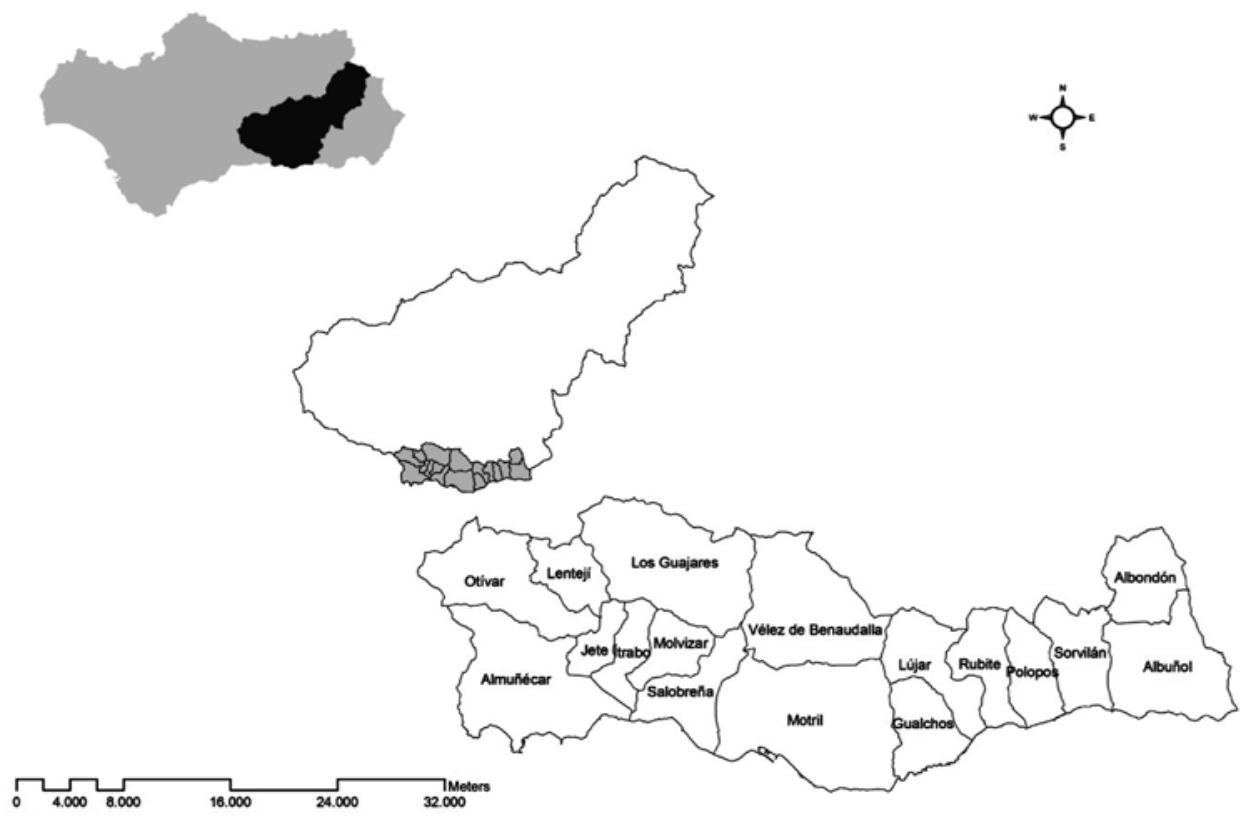

Fuente: Elaboración propia.

dos restantes totalmente de interior. La cabecera comarcal por su peso político, económico y demográfico es la ciudad de Motril -60.887 habitantes- (AA.VV., 2011).

Se caracteriza por presentar un clima cálido, con temperaturas suaves en los meses invernales que le permite contar con turismo todo el año. Esta climatología propia de un clima mediterráneo subtropical es favorable para el desarrollo de la agricultura de frutos tropicales como el chirimoyo (producto único en Europa), aguacate, níspola, mango y plátano entre otros.

La costa presenta características que la distinguen de las demás de Andalucía: cuenta con una franja litoral de $72 \mathrm{~km}$, de los cuales el 34,7\% son playas y el 62,3 lo constituyen acantilados, ramblas y vegas, lo que le confiere una diversidad y una belleza paisajística particular.

El turismo en la costa tropical es la segunda actividad económica después de la agricultura. La oferta de alojamiento turístico de la Costa Tropical es de 12.539 plazas (SIMA, 2010). Esta casi ha duplicado su número respecto a 1991 que se cifraba en 7.553 plazas. El mayor incremento se ha presentado en el alojamiento hotelero al pasar de 1.641 a 5.658 plazas, sin embargo existe una deficiencia en hoteles de categoría 5 estrellas, lo que pone en desventaja a la costa granadina. La mayoría de las plazas se concentran en Almuñécar y Motril que representan el 82,63\% del total, donde Almuñécar destaca con una mayor cantidad de plazas de hotel (3.735), mientas que Motril oferta una mayor cantidad de plazas de camping (1.962), el tercer municipio es Polopos 
con el 6,45\% del total con 810 plazas, por lo que se puede observar que la distribución de plazas de alojamiento en la costa es bastante desigual, con una oferta hotelera concentrada en Almuñécar.

En lo que respecta a la segunda vivienda o turismo residencial, existen un total de 30.350 viviendas secundarias (SIMA, 2001), de estas Almuñécar, Salobreña y Motril concentran el 90,86\% de las viviendas secundarias de la costa de Granada. A pesar de que se han realizado esfuerzos para equilibrar la oferta hotelera respecto a la segunda residencia, Almuñécar se sitúa como el quinto municipio español de más de 20.000 habitantes con mayor porcentaje de viviendas secundarias con el 53,2\% (INE, 2013), por lo que todavía existe mucho trabajo por hacer en este sentido. Algunos autores han caracterizado a la costa de Granada con un desarrollo turístico basado en la segunda residencia (García Manrique, 2000; Rebollo, 2001), esta es una de las causas por las que ha perdido competitividad respecto a otros destinos de litoral.

En el año 1997 se aprobó el plan de excelencia turística de Almuñécar con 2,70 millones de euros. En el 2000 se aprobó el plan de dinamización turística para la Costa Tropical de Granada con una inversión de 5,77 millones de euros (Beas Secall, 2012), estos dos hechos posibilitaron que se diera un impulso a la costa en cuestión de infraestructura turística, crecimiento de la oferta de alojamiento, diversificación de la oferta complementaria, así como de la oferta de ocio entre otros. Román Márquez (2011), resalta el hecho que en el plan de excelencia de la costa tropical, no se destinaron recursos a políticas de marketing y comunicación turística como un reflejo de la ausencia de la oferta turística de calidad en la zona.

La Costa de Tropical de Granada, la Costa del Azahar (Castellón) y la Costa de la Luz (Huelva), están consideradas turísticamente como costas emergentes, ya que reflejan un crecimiento en el número de pernoctaciones y de crecimiento de la oferta (Anton Clavé, op cit.), mejores niveles de conservación de sus valores paisajísticos, medioambientales y cuentan con una cantidad importante de recursos. Sin embargo como afirma Santos Pavón (2010:192), los destinos emergentes parecen preservar un modelo caduco pero que todavía ofrece resultados económicos positivos a corto plazo (ya que todavía le queda un amplio margen de crecimiento), cuestiones que se reflejan en el urbanismo expansivo con los fuertes impactos ambientales y paisajísticos al urbanizar laderas en las colinas litorales, los acantilados y las playas, situación que desde los años noventa hacía patente Martín-Vivaldi Caballero (1998). La agricultura también ha contribuido al deterioro del paisaje al entrar en competencia con el desarrollo turístico por la especulación del suelo.

Turísticamente se distinguen tres grandes áreas con diferente nivel de desarrollo (Sánchez Escolano y Espinosa Arias, 2012). En primer lugar se encuentra la parte más desarrollada, que es la parte de la costa occidental integrada por los municipios de Almuñécar, Motril y Salobreña, esta zona concentra el 87,47 \% de la oferta turística de la costa y dentro de esta Almuñécar oferta 6,606 plazas que representan el 52\% del total, es el de mayor tradición y cuenta con la categoría de municipio turístico. Aquí se encuentran las principales playas, las de mayores extensiones y mejores accesos. En esta zona existen un patrimonio histórico importante, como el Castillo de San Miguel, el acueducto romano, la fábrica de salazones, el Castillo de Salobreña, museos y una 
serie de torres de defensa. Cuenta con el puerto de Motril (comercial y de pasajeros), que poco a poco va teniendo más importancia como puerto de pasajeros con un total de 26 cruceros y 8.998 pasajeros durante el 2011 (AA.VV., 2012), el más próximo a Madrid de los puertos andaluces. Existe un puerto deportivo y un campo de golf, también se cuenta con la mayor cantidad de restaurantes, cafeterías e infraestructura de ocio y diversión (acuario, parque acuático). En esta zona existen áreas naturales protegidas como la Charca de Suarez, Cerro Gordo o los acantilados y fondos marinos de la Punta de la Mona.

Las características climáticas permiten el cultivo de frutos tropicales como el chirimoyo, aguacate, níspola, mango, lichi, plátano y algunos otros más. El chirimoyo es el principal cultivo con una producción de $49.000 \mathrm{Tm}$ y 3,125 has cultivadas (AA.VV., 2010). Este es un producto único en Europa. Se cuenta con la «Denominación de Origen Protegida Chirimoya Costa Tropical», el Consejo Regulador de la Denominación de Origen lo ha promovido por medio de talleres, degustaciones y elaboración de productos (helados, sopa, repostería), sin embargo turísticamente, no ha destacado para obtener una ventaja competitiva para la región.

El paisaje agrícola también juega un papel importante para el turismo, esta zona forma parte del imaginario de la costa, Calatrava Requena (1996) en un estudio con la población local sobre la valoración del paisaje en la vega Motril-Salobreña, encontró que la caña de azúcar, las actividades hortícolas tradicionales (huerta) y los cultivos de frutas tropicales son los que tienen mayor valoración como paisaje en la zona, por su parte López Moreno (2010), obtuvo como resultado que el paisaje agrícola en Almuñécar fue el más valorado entre los turistas (cultivos tropicales en vega y ladera), muy por encima de otras zonas agrícolas o seminaturales, por lo que la conservación y mantenimiento de la actividad y el paisaje es de gran importancia para la actividad turística.

La importancia de la actividad agrícola y turística se refleja en una fuerte competencia por el agua, que se manifiesta significativamente en los meses estivales, cuando existe una gran afluencia de turistas que llega a duplicar a la población local y la demanda de riego agrícola es mayor para los cultivos tropicales (Calatrava Leyva, 2005; Pérez Campaña, 2011).

La segunda gran área se encuentra en la parte oriental, integrada por los municipios de Gualchos, Lújar, Rubite, Polopos, Sorvilán y Albuñol. Aquí la oferta de alojamiento turístico es muy incipiente, Polopos ofrece la mayor cantidad de plazas con 810, Gualchos oferta 442 y Albuñol 128, en total 1.428 plazas de las cuales el 74,15\% son de camping. Este rezago en infraestructura hotelera se debe a ciertas limitaciones que impiden el desarrollo, las cuales son: a) la accidentada orografía del terreno que conforma una costa acantilada; b) insuficiente comunicación e integración con la parte occidental; y c) una fuerte competencia por el poco espacio disponible entre el turismo y los cultivos de invernadero que tienen una presencia muy importante en esta zona y que son el principal motor económico, pero totalmente incompatible con el turismo, debido a la gran contaminación del agua (insecticidas, fertilizantes), contaminación de residuos (plásticos principalmente), alteración del paisaje que provocan dichas instalaciones ubicadas en ramblas, laderas y colinas. 
En esta área, los municipios presentan una característica muy especial por tener en su territorio costa y montaña, la parte baja se presenta con características de pueblos costeros (pesca tradicional), mientras que la parte alta está integrada a la Alpujarra baja, una comarca histórica de gran riqueza cultural y patrimonial que se refleja en su gastronomía, fiestas y trazado urbano. Cabe destacar que diversas instituciones han integrado un comité para realizar las gestiones buscando obtener el reconocimiento de la Alpujarra como patrimonio mundial de la humanidad, figura que de obtenerse, sin duda dará un gran impulso a la región.

En esta parte del litoral existen pocos espacios para playas, de las cuales, varias tienen difícil acceso, sin embargo su belleza paisajística radica en los acantilados, zonas que son propicias para la práctica del submarinismo.

A lo largo de la costa se encuentran una serie de torres vigías y fuertes de defensa (Torrenueva, Castell de Ferro, Castillo de Baños, Castillo de la Rábita) considerados como bienes de interés cultural. También existen zonas arqueológicas como la Cueva de los murciélagos (Albuñol) o la Cueva de las Campanas (Gualchos). Cuenta con una red de senderos que permite recorrer la sierra de la Contraviesa o la sierra de Lújar, donde se encuentra el bosque de Alcornoque más alto de la península ibérica, por su gran valor está declarada como área natural protegida, en esta misma categoría se encuentran los acantilados y fondos marinos de Castell de Ferro.

La sierra de la Contraviesa es famosa por su tradición en la elaboración del «vino de la costa» que tuvo su auge en el siglo XVIII y XIX, a lo largo de ella nos encontramos con una gran cantidad de producciones y bodegas familiares. En años recientes se han presentado iniciativas para rescatar esta tradición del cultivo de la vid y desarrollar cultivos más tecnificados y con mejores controles de calidad en pequeñas bodegas que apuestan por la calidad de sus productos, Barranco Obscuro, Los Martos, Nazaríes, Alpujárride, Cuatro Vientos y Llorente, ubicadas en la Sierra de la Contraviesa, apuestan a darle un impulso a esta región de gran cultura y tradición, evitando el abandono de tierras y generando mejores dinámicas locales. La mayoría de estas cuentan con la Denominación de Origen Protegida, «Vinos de Calidad de Granada». Algunas de estas bodegas, empiezan a innovar y están combinando las actividades del enoturismo con senderismo o ciclismo de montaña, asociando a empresas locales y así captar a un mayor número de visitantes.

La tercera gran área, la forman los municipios del interior, la integran los municipios de Otívar, Lentegí, Jete, Ítrabo, Molvízar, Los Guájares, Vélez de Benaudalla (parte occidental) y Albondón (parte oriental), la oferta de alojamiento turístico es prácticamente inexistente, destaca Vélez de Benaudalla que oferta 115 plazas, seguido con Otívar con 17, finalmente, los Guájares con 11 plazas. Su principal actividad económica se basa en el cultivo de frutos tropicales en los municipios accidentales y en los cultivos de secano y de vid en Albondón.

Esta zona tiene un gran potencial por sus recursos naturales y culturales, como el parque natural de las Sierras de Tejeda, Almijara y Alhama, o la sierra de los Guájares, zonas propicias para realizar actividades de naturaleza o turismo activo. Aquí se encuentran el Río Verde y el Río Lentegí ideales para realizar la actividad descenso de barrancos y cañones, o la actividad de parapente, municipios con agua abundante como 
los Guájares (Río Toba, caídas de agua, senderos homologados), o Vélez de Benaudalla con una gran cantidad de fuentes (ruta del agua) y la presa de Rules donde se pueden implementar actividades y deportes acuáticos. Esta zona cuenta con una amplia red de senderos de corto recorrido y locales donde se puede practicar el senderismo y el ciclismo de montaña. Por sus características del territorio, vegetación y paisaje se realizan distintas competencias en el medio natural durante el año.

En patrimonio destaca el Castillo de Vélez de Benaudalla, el Castillo de Venta de la Cebada y el jardín Nazarí. Además de diferentes fiestas y celebraciones como el festival de música tradicional de la alpujarra, que en este año se celebrará en Albondón, también se encuentra la fiesta del vino (Ítrabo) o la feria de la Níspola (Otívar) con el fin promocionar los productos locales.

Esta zona también tiene una tradición en el cultivo de la vid, principalmente en los municipios de Ítrabo y Molvízar, donde existen bodegas familiares, entre las que destaca la Bodega Calvente ubicado en el municipio de Jete, como productor con Denominación de Origen Protegida, «Vinos de Calidad de Granada».

A modo de resumen nos encontramos una Costa de Granada con una gran riqueza en su patrimonio natural y cultural aún por descubrir, que da cuenta de 54 bienes inscritos en el Catálogo General del Patrimonio Histórico Andaluz, siete espacios naturales protegidos, propicios para la práctica de turismo de naturaleza (senderismo, ciclismo de montaña, descenso de barrancos, submarinismo). Una amplia red de senderos en prácticamente todos los municipios, una gran riqueza cultural que se manifiesta en sus diferentes fiestas, una gastronomía diversa y de calidad. Con productos únicos como el chirimoyo y los frutos tropicales (aguacate, níspero, mango).

Aprobado en fechas recientes, el Plan de Ordenación del Territorio de la Costa Tropical de Granada (2011), es el documeneto regulador del desarrollo del territorio, que si bien tiene varios puntos de mejora (Sánchez Escolano, 2011), es el documento rector para el crecimiento ordenado y sostenible.

Sin embargo existen grandes temas pendientes en cuestión de infraestructura de comunicación que requieren ser atendidas; La terminación de la Autovía del Mediterráneo (A-7) para poderse conectar con la provincia de Málaga y con la de Almería. La finalización de la autovía hacia la costa (A-44) y su enlace con la A-7. Esta desarticulación física requiere una atención inmediata para que la costa pueda ser más competitiva. Otro asunto pendiente y que se ha convertido en un verdadero «enclavamiento» que favorece a los competidores más próximos, es el ferrocarril de Motril a Granada para enlazar su puerto, que cada día cobra mayor importancia en el transporte de pasajeros y es el único puerto de toda la península ibérica sin vía ferroviaria.

A pesar de las alteraciones del paisaje, los impactos ambientales, un desarrollo turístico concentrado en la parte del litoral occidental y la falta de infraestructura de comunicaciones, la costa de Granada cuenta con una cantidad importante de recursos naturales y culturales, que manejados integralmente y de una manera sostenible pueden contribuir a constituirse como un destino turístico relevante. Por lo que vale la pena realizarse la pregunta ¿Por qué la costa Tropical de Granada no se ha desarrollado turísticamente?

Una de las formas de abordar esta pregunta es conociendo la percepción del turismo por parte de los actores locales. Este tipo de abordaje ha sido empleado por Vera Rebo- 
llo, Díez Santo e Ivars Bidal (2009), para conocer percepción de los agentes actuantes de la política turística en los municipios del interior de la comunidad Valenciana, encontraron que uno de los factores importantes para el desarrollo del turismo en cuestiones de ordenación son las prácticas de complementariedad territorial, mientras que en relación con la política turística, la colaboración supramunicipal es fundamental para los municipios pequeños. Huete Nieves, Mantecón Terán y Mazón Martínez (2008), han realizado un trabajo sobre la percepción del turismo residencial en el litoral de Alicante, concluyendo que el discurso dominante se encuentra más cercano a la legitimización del turismo residencial. Gutiérrez Taño y Díaz Armas (2010), han enfocado el trabajo de la percepción de los residentes hacia el turismo en Canarias. Por su parte Rodríguez González (2007), realizó un trabajo sobre la percepción social del turismo en Andalucía, enfocado en grupos de litoral, montaña y ciudad, tratando de cubrir los territorios más característicos del turismo andaluz.

\section{METODOLOGÍA}

Se efectuaron entrevistas semiestructuradas a los alcaldes de los 17 municipios que integran la costa de Granada, con el fin de conocer desde su perspectiva la situación del turismo, las problemáticas y posibles soluciones. Las entrevistas se realizaron en el periodo comprendido entre marzo del 2012 a septiembre del 2013, excepto las realizadas a los municipios de Otívar, Lentegí y Jete que se llevaron a cabo de mayo a septiembre del 2010. El periodo de entrevistas está marcado por muchos cambios en las políticas del país como consecuencia de la crisis; estos son entre otros la propuesta de ajuste y desaparición de las mancomunidades por parte del Gobierno de España, la propuesta de reducción de municipios pequeños, las cuales finalmente no se concretaron, pero que estuvieron en el debate público.

El contenido de la entrevista abarcó la identificación de los atractivos, potencial turístico, problemáticas y posibles soluciones; tipología del visitante, población extranjera, colaboración municipal y supramunicipal, visión de desarrollo turístico y acciones para el desarrollo turístico. Las entrevistas fueron grabadas (con excepción de dos), las transcripciones y revisión corrió a cargo del entrevistador.

Las transcripciones de las entrevistas se procesaron con el programa de análisis textual de datos Alceste 2014 versión plus education. Alceste significa «análisis lexical de co-ocurrencias en enunciados simples de texto» este programa se utiliza para el análisis de entrevistas, encuestas, artículos de revistas o periódicos, ensayos y obras literarias entre otros.

El programa se basa en la distribución estadística de sucesiones de palabras que componen los enunciados de un texto, sin tomar en cuenta la sintaxis del discurso, sino únicamente la co-ocurrencia (Reinert, 1993) o presencia simultánea de varios ítems (sustantivos, adjetivos, verbos), en un mismo enunciado, eliminando del análisis las palabras herramienta (conjunciones, preposiciones, artículos, negaciones, etc.).

Para efectos prácticos el programa divide el texto en pseudo-enunciados llamados Unidades de Contexto Elementales (UCE), formados por secuencias de 8 a 20 ítems lexicales (sustantivos, adjetivos, verbos). El principal procedimiento estadístico que 
elabora este programa es la clasificación jerárquica descendente (similar al cluster analysis), técnica derivada del análisis factorial de correspondencias del cual se pueden llevar a cabo otros análisis complementarios (Alba, 2004).

La ventaja Alceste es la clasificación que arroja el programa, ya que esta se da sin intervención del investigador evitando las preconcepciones que «alteren» el análisis.

Para asegurar la confiabilidad de la clasificación del discurso el programa realiza una doble clasificación jerárquica descendente con unidades de contexto de determinado tamaño, en este caso de 10 palabras para la primera y 12 para la segunda (por ejemplo), teniendo así unidades de contexto de tamaños distintos. La clasificación es estable si esta variación del tamaño del vocabulario por unidad de contexto elemental (UCE) no cambia la estructura o distribución de las clases ni su contenido.

Uno de los resultados principales de alceste es el dondograma que es la gráfica que indica el número de clases, su estructura y forma de relación entre ellas (Alba, op cit). La lista de palabras de acuerdo a su grado de asociación de cada clase (chi_cuadrado), las palabras incluidas al principio de cada clase son las que definen más la clase (Alceste solo toma en cuenta para el análisis principal las raíces de palabras, por lo que las palabras aparecen cortadas con el símbolo «+», lo cual indica que se han eliminado las terminaciones). También se incluye el porcentaje de UCE que incluye cada clase, esto permite observar la cantidad de texto que ocupa cada clase en el discurso.

La intervención del investigador para la interpretación sobre el contenido de las clases, así como sus nombres se realiza a partir principalmente del dendograma, pero con la ayuda de análisis complementarios que proporciona el programa, como análisis factorial de correspondencias múltiples, fragmentos de texto representativos de cada clase o frecuencia de palabras.

\section{RESULTADOS Y DISCUSIÓN}

El programa arroja una clasificación jerárquica descendente de 3 clases (figura 2), la cual agrupa al $74 \%$ de UCE.

La doble clasificación jerárquica descendente con unidades de contexto fue de 11 palabras para la primera y 13 para la segunda. La clasificación fue idéntica en los dos casos, con 3 clases cada una y la misma estructura de relación entre ellas, por lo que se puede considerar como una clasificación jerárquica descendiente confiable.

En el dendograma se observan dos discursos claramente definidos; en el primero se encuentra el discurso de Político administrativo, como funciones de gobierno de los ayuntamientos, referente a la gestión municipal con otros organismos (clase 2) y el Desarrollo territorial, centrándose principalmente en el desarrollo del turismo (clases 3).

En el segundo se encuentra el discurso relacionado con la actividad turística (clase 1), como actividad un poco ajena a la gestión municipal al estar separada de las clases 2 y 3 .

La clase 2 reagrupa el 19\% de las unidades de contexto analizados por el programa, esta clase se orienta a la gestión municipal con la Mancomunidad de Municipios de la Costa, los grupos de desarrollo rural, la Diputación y el Patronato Provincial de Turismo de Granada.

La clase 3 presenta el $25 \%$ de las unidades de contexto, hace clara referencia a cuestiones de planeación y ordenación del territorio. 
Figura 2

DENDOGRAMA PALABRAS INCLUIDAS EN CADA CLASE, SEGÚN FUERZA DE ASOCIACIÓN

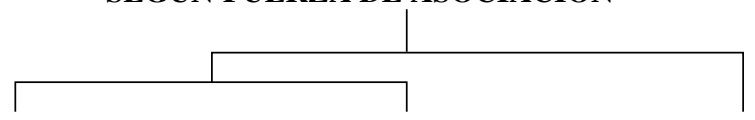

Clase 2

(19\% de uce)

Gestión
Clase 3

(25\% de uce)

Desarrollo territorial
Clase 1

(56\% de uce)

Actividad turística

$\mathrm{Kchi}^{2}$

$\mathrm{Kchi}^{2}$

$\mathrm{Kchi}^{2}$

\begin{tabular}{|c|c|c|c|c|c|}
\hline mancomun & 125 & desarroll+ & 142 & gente & 78 \\
\hline tropical & 108 & plan & 130 & venir & 47 \\
\hline $\cos t+$ & 54 & zona & 55 & casa & 22 \\
\hline servicio & 49 & litoral & 52 & dia & 20 \\
\hline mancomunidad & 47 & golf & 51 & mayor & 20 \\
\hline conjun+ & 37 & ordenación & 51 & ruta & 19 \\
\hline diputación & 37 & subregional & 40 & pueblo & 19 \\
\hline colaboración & 37 & metro & 38 & ingles & 17 \\
\hline patrona & 33 & limit+ & 32 & extranjero & 17 \\
\hline conjunta & 30 & territorio & 32 & visit+ & 15 \\
\hline agua & 29 & orografía & 31 & produc+ & 14 \\
\hline misma & 29 & deportiv+ & 30 & trabaj+ & 14 \\
\hline municipio & 27 & turis+ & 29 & año & 13 \\
\hline papel & 24 & terreno & 29 & bodega & 13 \\
\hline ayuntamiento & 22 & infraestructura & 29 & fiesta & 13 \\
\hline guerra & 21 & urbanist+ & 27 & lleg+ & 12 \\
\hline sierra & 21 & playa & 26 & compr+ & 12 \\
\hline compart+ & 21 & sector & 24 & integr+ & 12 \\
\hline comun & 20 & puert+ & 23 & person+ & 12 \\
\hline foment+ & 20 & inversor & 22 & restaurante & 12 \\
\hline interes & 20 & industrial & 22 & pasa & 11 \\
\hline independiente & 20 & ordenamiento & 22 & si & 10 \\
\hline otros & 18 & agricola & 21 & joven & 10 \\
\hline supon+ & 17 & actuación & 21 & chirimoy & 10 \\
\hline función & 17 & oportunidad & 21 & vez & 9 \\
\hline acciones & 17 & aprob+ & 21 & niño & 9 \\
\hline distinta & 17 & area & 18 & rumano & 9 \\
\hline
\end{tabular}

Fuente: Alceste, elaboración propia. 
La clase 1 integra al 56\% de las UCE de esta clase, de acuerdo a las palabras que la componen (gente, venir, casa, día, mayor, ruta, pueblo) se puede apreciar la referencia hacia los turistas y la actividad relacionada con las rutas, las bodegas, las fiestas.

Para realizar mejor la interpretación se presentan las unidades de contexto más representativas de cada clase. El orden de presentación de las clases obedece a la ubicación en el dendograma (izquierda a derecha).

\subsection{Clase 2: Gestión}

En esta clase se formaron 3 grupos de vocabulario los cuales son de gestión; colaboración, conjun+, acción, función, fomento, compartir. De relación; mancomun, diputación, municipio, ayuntamiento, patronato, finalmente de lugar; tropical, costa, sierra.

«Tenemos una provincia que tiene pues lo que cualquier turista puede ir buscando desde agroturismo, tenemos la sierra, tenemos el mar».

«L colaboración con otros municipios para proyectos conjuntos de turismo. $Y$ de hecho lo hacemos. Principalmente sabe usted que estamos dentro de lo que es el marcado de la costa tropical».

«Eso es una cuestión más política que otra cosa. La mancomunidad como ente está funcionando y va a seguir haciéndolo independientemente de lo que políticamente cada uno determine. Toda la colaboración se mantiene en la mancomunidad. Los municipios pequeños como que se sienten, bueno este es un punto mío, se sienten un poco abandonados».

«Eso es lo que nos falta, la colaboración con los otros municipios de la región para proyectos de desarrollo. Eso te comentaba antes que quizá nos faltaría sentarnos y hacer proyectos macro municipales, más que pensar en cada uno por su pellejo, cada uno por sí solo».

«Hombre yo pienso que desde que yo estoy aqui la mancomunidad ha servido poco, vamos fundamentalmente ha servido para mancomunarnos dos servicios: uno que es el agua y otro la recogida de basura».

Tanto en el vocabulario, como en los fragmentos más representativos del discurso de esta clase, existe una identificación a las características de la costa (sierra, mar, clima), principales activos de venta de la marca costa tropical. Se observa que la Mancomunidad de Municipios de la Costa Tropical tiene un lugar preponderante en relación a los servicios mancomunados como son el agua y la recogida de basura, servicios que se encuentran consolidados. Existe interés por realizar trabajo conjunto en cuestión de turismo, este se realiza en las instancias establecidas como son: los grupos de desarrollo rural, la diputación y la mancomunidad de municipios de la costa, esta última es la que aprecian los alcaldes como la más adecuada para coordinar los trabajos de planificación turística e impulsar el desarrollo de la región. De igual manera existen algunas diferencias entre los ayuntamientos sobre el funcionamiento al interior de la mancomunidad, abandono de los municipios pequeños, falta de integración y de una visión común del desarrollo turístico en la mancomunidad. 


\subsection{Clase 3: Desarrollo territorial}

Las palabras; desarroll+, zona, cost+, plan, playa, hacen una clara alusión a cuestiones de planificación y ordenación territorial, donde existe por algunos actores la preocupación por el desarrollo de la segunda residencia en la primera línea de playa, y por tratar de conservar lo natural sobre lo turístico. Se reconoce un desarrollo desigual en los municipios que integran la costa de Granada.

«Hombre nosotros en nuestro planteamiento urbanístico si queremos acotar las zonas de construcción de invernaderos, son importantes o podrían alimentar el desarrollo turístico. En cierto modo son poco compatibles, en montar un desarrollo turístico natural con la implantación de invernaderos».

"La economía debe de diversificarse y no tener una dependencia absoluta de un sector. Aquí la agricultura está generando mucho empleo y además está generando mucha actividad económica. Y es bueno hacerlo desde la ordenación previa, desde la ordenación urbanística previa, pero creo que pueden coexistir en un municipio la agricultura y el turismo perfectamente».

«Si aquí quitas alrededor de 200 o $250 \mathrm{~m}$. de explotación dejamos el pueblo sin futuro, es totalmente importantísimo y la que no se vea afectada de grandes influencias económicas, sino simplemente es en la materia prima que necesitamos para salir adelante, todo lo demás sale de la agricultura».

«A nosotros nos limita mucho el plan de ordenación de la costa, yo entiendo de que tenemos que andar en un compendio entre el desarrollo y el medio ambiente pero no deja de que nosotros con la orografía que tenemos. Es que a nosotros al principio nos mandaban a quinientos metros del litoral».

«Esa masificación de segunda residencia en primera línea de playa que no genera riqueza, nosotros también tenemos parte, pero hemos sabido preservar grandes zonas en frente del litoral para darle un uso más turístico, hotelero, que no residencial».

"Que es un complejo que va a llevar a parte del puerto deportivo, unos importantísimos amarres, 800 amarres, pues va a tener un hotel, va a tener zonas comerciales, zonas de ocio».

Como se puede apreciar el discurso manejado en esta clase, la agricultura bajo plástico es de gran importancia económica en la región, sin embargo el crecimiento sin planeación está provocando que varios ayuntamientos en sus planes generales de ordenación urbanística municipales los estén regulando para tratar de compatibilizarlo con el turismo y los invernaderos. Existe una desigualdad en el desarrollo del turismo de la parte occidente donde se encuentra la mayor parte de la infraestructura turística y en la cual se proyectan algunos desarrollos de golf, puerto deportivo, e infraestructuras de primer nivel, respecto a la parte oriental con menor infraestructura debido a su orografía de acantilados y pocos espacios de playa, que ven como un problema el recién aprobado Plan de Ordenación del Territorio de la Costa Tropical de Granada (20 de diciembre del 2012), debido a que limita la construcción en la primera línea de playa, ya que en su caso los trasladaría a la parte de la sierra. 


\subsection{Clase 1: Oferta turística}

El vocabulario en esta clase se refleja en 3 rubros, el primero con referencia al visitante con las palabras; gente, venir, casa, llegar. El segundo relacionado con la tipología del turista; mayor, extranjero, inglés, el tercero se relaciona con la actividad turística propia; ruta, pueblo, produc+, bodega, fiestas, comprar, restaurante, chirimoyo.

"No es lo mismo que te vas a La Herradura o a Almuñécar y hay un extranjero que lleva viviendo 20 años y no lo conoce nadie. Aquí los que hay conocen perfectamente a la gente del pueblo, pero no hay una amistad, a ellos les gusta vivir su vida más independiente».

«Tenemos extranjero que viene a trabajar a la agricultura, no hay mucho pero si sobre todo es rumano, rumanos que están trabajando en la agricultura y que están ya integrados aquí la mayoría».

«Son personas mayores. Luego también se ven gente que se vienen a pasar la mañana y se va las rutas de senderismo que hay, en verano suele venir más gente porque como hay mucha gente fuera».

«También nos encontramos una serie de ciclo turistas que todos los fines de semana, que es más gente joven que discurren por estos senderos y caminos. $Y$ son visitantes nacionales en su mayoría».

«De los visitantes que llegan al municipio, normalmente vienen más personas mayores que jóvenes, pero últimamente con el tema este de lo que es barranquismo, hacer las rutas y todo esto, pues se ve bastante joven también».

«Este concurso del choto, la mayoría es gente de fuera. Llevamos quince años. Vienen por lo menos mil quinientas personas, toda la plaza».

«Se hace una visita a esas bodegas y se hacen unas degustaciones y tenemos el centro de interpretación de la caña de azúcar. $Y$ ahora lo vamos a complementar con esa visita a la finca experimental para que la gente pueda también ver la caña de azúcar y degustarla».

«Sobre la feria del vino, vienen como mil personas. Pues si no me equivoco creo que este año es, 15 años llevamos ya. Ha ido creciendo. Aquí en este pueblo ahora ya menos pero este pueblo ha vivido de la almendra y del vino, yo me acuerdo de pequeño».

«Y los precios que ves tú en el mercado de chirimoya bastante dices bueno cuanto es el costo del agricultor, tremendo aquí el municipio estos municipio viven porque son gente que están acostumbradas a sufrir, a trabajar mucho».

«Las chirimoyas, los mangos, como son todos los productos subtropicales que insisto en toda Europa solamente se pueden ver aquí. Tener también cañas de azúcar, porque también se haría una degustación de ella».

«Viene la persona y ellos le dan alojamiento y comida y se dedican a las tareas diarias del agricultura, aunque también una gran red de caminos rurales que se pueden realizar excursiones con bicicleta o a caballo y todas las cosas». 
«En la cooperativa a la que pertenezco si tendría interés en el futuro de tener turismo de cómo se envasa y eso. Sí, sí, nosotros solemos llevar gente. Ayer tuvimos una visita de la escuela de adultos de Canarias, de Palma de Mallorca y de Teruel».

En esta clase, se reflejan más temas abordados por los alcaldes, debido a que fue el mayor porcentaje de unidades de contexto analizadas (56\% UCE), los temas son la relación de los residentes extranjeros que viene a pasar temporadas vacacionales, principalmente ingleses, que han adoptado algunas costumbres españolas, pero no el lenguaje o la convivencia, ya que en su mayoría son personas mayores jubilados. En contraste se encuentran los extranjeros que vienen a trabajar y por esta misma circunstancia se integran y conviven con la población local. En relación al perfil de los visitantes son personas mayores que normalmente asisten entre semana a recorrer el pueblo o realizar senderismo, mientras que los fines de semana acuden personas más jóvenes a practicar actividades como clicloturismo, barranquismo o senderismo. Sobre la potencialidad turística de la zona; se reconoce por parte de los entrevistados y tanto en los productos únicos como el chirimoyo o los frutos tropicales, en las tradiciones como la producción del vino y las celebraciones relacionadas con éste. Festivales gastronómicos o rescate de cultivos como la caña de azúcar en fincas experimentales. Se manifiesta la problemática de la comercialización de los productos agrícolas debido al bajo precio de pago a los agricultores. Se puede ver como surgen nuevas iniciativas como visita a fincas y degustación de frutos tropicales, el agroturismo o la visita a las envasadoras para conocer el proceso de empaque de los productos agrícolas.

El análisis realizado con el programa Alceste, arrojó la siguiente información; el discurso lo clasifica en dos grandes bloques; el primero lo forman dos clases relacionadas con la gestión (clase 2) y el desarrollo territorial (clase 3), mientras que segundo bloque está formado por la actividad turística (clase 1). Se reconoce la diversidad de la costa como atractivo turístico (mar, clima, sierra). Se aprecia que los organismos supramunicipales como la mancomunidad de municipios de la costa, son una figura de gran importancia en la zona, ya que además de realizar la función de los servicios como agua y recogida de basura, los alcaldes la identifican como la instancia principal para la planeación turística, coincidiendo con los afirmado por Vera Rebollo, et al (2009) y Cebrián Abellán, 2006), sobre importancia de los organismos supramunicipales en los municipios para el desarrollo del turismo. Por su parte Figueras Riera, Hass, Amer Capdevila y Villaplana, (2005), afirman que las mancomunidades son la entidad local supramunicipal de mayor implantación en España, ya que nacen como entidad local de cooperación voluntaria intermunicipal. En este sentido se posiciona a la mancomunidad para desarrollar el turismo en la costa de Granada, por encima de la diputación o los grupos de desarrollo rural. Sin embargo varios alcaldes manifiestan los problemas de integración, coordinación, visión y falta de liderazgo. Éste no es un asunto exclusivo de la costa, varios autores hacen referencia en la falta de coordinación entre las administraciones en sus diferentes niveles como uno de los problemas a los que se enfrenta el turismo español (Anton, 2004; Pulido Fernández, 2011; Pirelli del Amo, 2011; Vera Rebollo, et al, 2011). Por otro lado se encuentran identificados los problemas y existe disposición a resolverlos, por lo que se vislumbra 
que la mancomunidad puede ser una palanca del desarrollo turístico, porque deben ser los gobiernos los que impulsen las iniciativas de desarrollo, para generar más liderazgos con otros actores sociales y de la iniciativa privada. Existen ejemplos de éxito en el ámbito turístico, en la implementación de políticas públicas y a la coordinación entre las diferentes instancias públicas, uno de estos es el del parque regional de Sierra Espuña en Murcia (Cebrián Abellán y García Marín, 2009), donde la integración de la mancomunidad de municipios, ha sido una parte fundamental para la coordinación entre los diferentes actores públicos y privados. Otro caso es el del consorcio administrativo «La Manga», como un nuevo tipo de liderazgo que deben asumir las administraciones (Espejo Marín y García Marín, 2011). Estos ejemplos pueden ser una guía que facilite el tránsito de la mancomunidad hacia una integración y visión común del desarrollo turístico de la costa de Granada.

Se refleja en el discurso la importancia de la actividad económica de la agricultura, pero empieza a notarse la necesidad de un ordenamiento de la actividad, sobre todo en los cultivos bajo plástico. En este sentido el Plan de Ordenación del Territorio de la Costa Tropical de Granada, es un instrumento de gran utilidad, ya que es el documento rector para el crecimiento ordenado y sostenible (Sánchez Escolano, 2011). Sin embargo en los municipios que tienen zonas acantiladas ven que este instrumento frenara los posibles proyectos de desarrollo, cuestiones que se tendrán que compatibilizar en el futuro próximo

El perfil de los residentes es de personas mayores, jubilados de países europeos más nórdicos. Respecto a los visitantes de fin de semana son personas más jóvenes y realizan actividades como cicloturismo, senderismo, barranquismo entre otros. En la oferta turística destaca la oportunidad que se encuentra en el turismo rural, el desarrollo de bodegas y productos con denominación de origen. Estas actividades se ven como un aliciente al trabajo que representa el campo y lo poco redituable que suele ser para el productor. Finalmente están surgiendo nuevas iniciativas como visita a fincas y degustación de frutos tropicales, el agroturismo o la visita a las envasadoras para conocer el proceso de empaque de los productos agrícolas.

Para obtener una visión más completa sobre el desarrollo turístico en la costa de Granada, se deben de realizar otros estudios que involucre a una mayor cantidad de actores locales y regionales (asociaciones, organismos supramunicipales, empresarios), así como la utilización de otros métodos y técnicas.

\section{A MODO DE CONCLUSIÓN}

La costa de Granada cuenta con recursos naturales y culturales para poder desarrollar la actividad turística. La aprobación de plan de ordenación de la costa tropical de Granada es una herramienta que permitirá hacerlo de una manera más sostenible. En este sentido, existe la visión de algunos alcaldes de ordenar el territorio para diversificar las actividades.

La mancomunidad de municipios de la costa de Granada juega un papel preponderante en el turismo. Se acepta entre los alcaldes a la mancomunidad como el principal organismo para la planeación del desarrollo turístico de la región. Pero no se comparte 
una visión común y liderazgo. Se percibe entre varios integrantes la disposición a resolverlos estos problemas, lo que se plantea como un futuro más favorable.

Es de suma importancia el desarrollo armónico de la mancomunidad como punta de lanza para que encabece el proceso de planeación y permita desarrollar otros liderazgos, ya que está comprobado que los gobiernos son los impulsores de las nuevas formas de administración.

Empiezan a surgir algunos proyectos de turismo rural como visita a las fincas, huertas e invernaderos como parte de la explotación de un segmento de agroturismo. Actividades como la visita a bodegas, el senderismo, descenso de barrancos, cicloturismo pueden dar resultados positivos, pero que requieren de una adecuada planeación.

Para la costa tropical de Granada la conclusión de la autovía del mediterráneo (A7), es un elemento impostergable para poder conectarla con las provincias de Almería, Málaga y con Granada capital y estar en condiciones de competitividad respecto a las otras provincias. Esta es una gestión que lleva 30 años sin ser una realidad.

Se requieren más estudios con un abordaje más amplio y completo de la costa de Granada que permita enriquecer las investigaciones desde diferentes perspectivas y contribuyan a una mejor toma de decisiones.

\section{BIBLIOGRAFÍA}

ANTON CLAVÉ, S. (2004): «De los procesos de diversificación y cualificación a los productos turísticos emergentes. Cambios y oportunidades en la dinámica reciente del turismo litoral», Papeles de Economía Española, n ${ }^{\circ} 102$, pp. 316-333.

AA.VV. (2010): Anuario de estadísticas agrarias y pesqueras de Andalucía, año 2010. Consejería de Agricultura y Pesca. Junta de Andalucía. Sevilla.

AA.VV. (2011): Padrón municipal de habitantes. INE, Madrid.

AA.VV. (2012): Turismo de cruceros en Andalucía, año 2011. Consejería de Turismo, Comercio y Deporte. Junta de Andalucía.

BEAS SECALL, L. (2012): «Los planes de excelencia turística en España (1996-2006). Una apuesta por la revitalización de los destinos. Revisión de su implantación e impactos», en Scripta Nova, vol. XVI, n 411, 20 de agosto de 2012. Universidad de Barcelona. Disponible en http://www.ub.edu/geocrit/sn/sn-411.htm

CALATRAVA REQUENA, J. (1996): «Valoración económica de paisajes agrarios: Consideraciones generales, aplicación del método de valoración contingente al caso de la caña de azúcar en la vega Motril - Salobreña», en Gestión de espacios naturales. La demanda de servicios recreativos. McGraw-Hill. Madrid. Pp. 143-172.

CALATRAVA LEYVA, J. y SAYADI, S. (2005): «Economic valuation of water and willingness to pay analysis in tropical fruit production in South - Eastern Spain», Spanish Journal of Agricultural Research, vol. 3, nº 1. Pp. 25-33.

CEBRIÁN ABELLÁN, A. (2006): «Ordenación turística y cooperación interinstitucional en la comunidad de Murcia», Nimbus, no 17-18, pp. 5-22.

CEBRIÁN ABELLÁN, A. y GARCÍA MARÍN, R. (2009): «El parque regional de Sierra Espuña (Murcia): Eficacia ambiental y turística», Nimbus, nº 23, pp. 45-60. 
CHOI, S., LEHTO, X. y OLEARY, J. (2007): «What does the consumer want from DMO website? A study of US and Canadian tourists' perspectives», International Journal Tourism Research, $\mathrm{n}^{\circ}$ 9, pp. 59-72.

DE ALBA, M. (2004): «El método Alceste y su aplicación al studio de las representaciones sociales del espacio urbano: El caso d ela Ciudad de México», Papers on Social Representations, $\mathrm{n}^{\circ}$ 13, p.p. 1.1-1.20.

ESPEJO MARÍN, C. y GARCÍA MARÍN, R. (2011): «La Manga Consorcio. Instrumento de gobernanza en un espacio turístico singular del sureste de España», en Seminario internacional. Renovación y reestructuración de destinos turísticos consolidados del litoral. Alicante, Universidad de Alicante, pp. 1-21.

EXCELTUR (2005): Estudio de los impactos socioeconómicos, ambientales y sobre el empleo del actual modelo de desarrollo turístico español del litoral mediterráneo, Baleares y Canarias. Madrid, Alianza para la Excelencia Turística (EXCELTUR) y Deloitte.

FIGUERAS RIERA, P., HAAS, C., AMER CAPDEVILA, C. y VILLAPLANA, V. (2005): «Las mancomunidades en España», Boletín de la Asociación de Geógrafos Españoles, n ${ }^{\circ} 39$, pp. 151-176.

GARCÍA MANRIQUE, E. (2000): «Los espacios turísticos del litoral andaluz», Cuadernos Geográficos, $\mathrm{n}^{\circ}$ 30, pp. 43-76.

GREENPEACE, (2010): Destrucción a toda costa 2010. Informe de Greenpeace sobre la destrucción del litoral español. Disponible en www.destruccionatodacosta.com.

GUTIÉRREZ TAÑN, D. y DÍAZ ARMAS, J. (2010): «Las actitudes de los residentes hacia el turismo en un destino maduro» en Destinos turísticos maduros ante el cambio. Reflexiones desde Canarias. La Laguna, Universidad de la Laguna, pp. 255-279.

HUETE NIEVES, R., MANTECON TERÁN, A. y MAZÓN MARTÍNEZ, T. (2008): «¿De qué hablamos cuando hablamos de turismo residencial?», Cuadernos de Turismo, no 22, pp. 102-121.

INE (2011): Encuesta de ocupación en alojamientos turísticos (establecimientos hoteleros). Datos definitivos 2010.

INE (2013): Censos de población y viviendas 2011. Edificios y viviendas. Datos provisionales. Notas de prensa, 18 de abril 2013. Disponible en http://www.ine.es/prensa/ np775.pdf

INSTITUTO DE ESTUDIOS TURÍSTICOS (2012): Informe anual 2011. Encuesta de Gasto Turístico (Egatur). Disponible en http://www.iet.tourspain.es/es-ES/estadisticas/egatur/Anuales/Movimientos\%20Tur\%C3\%ADsticos\%20en\%20Fronteras\%20 (Frontur)\%20y\%20Encuesta\%20de\%20Gasto\%20Tur\%C3\%ADstico\%20(Egatur)\%202011.pdf

LÓPEZ MORENO, J. (2010): Valoración económico-paisajística de la costa tropical andaluza (Tesis de Máster). Universidad de Sevilla. Sevilla. 58 págs.

MARTÍN-VIVALDI CABALLERO, M.E. y COZAR VALERO M.E. (1998): «Paisaje y turismo en el litoral de Granada» en El Paisaje Mediterráneo, Granada, Universidad de Granada, pp. 273-281. 
OBIOL MENERO, E. y PITARCH GARRIDO, M. (2011): «El litoral Valenciano. Intereses y controversias en un territorio tensionado por el residencialismo», Boletín de la Asociación de Geógrafos Españoles, $\mathrm{n}^{\circ}$ 56, pp. 177-200.

OBSERVATORIO DE LA SOSTENIBILIDAD EN ESPAÑA (2006): Cambios de ocupación del suelo en España, implicaciones para la sostenibilidad. Ministerio del Medio Ambiente, Fundación Biodiversidad y Fundación Universidad de Alcalá.

OJEDA ZUJAR, J. y VILLAR LAMA, A. (2006): «Evolución del suelo urbano/alterado en el litoral de Andalucía (España) 1998-2002», Geofocus, no 7, pp. 73-99.

PÉREZ CAMPAÑA, R., VALENZUELA MONTES, L.M. y MATARÁN RUIZ, A. (2011): «Fundamentos para la innovación en la gestión de los espacios agrarios periurbanos del litoral Mediterráneo», Quivera, n $^{\circ} 13$, pp. 63-82.

PIRELLI DEL AMO, O. (2011): «Por una nueva cultura del litoral basada en su revaloración turística como motor de la recuperación», Papeles de Economía Española, $\mathrm{n}^{\circ} 128$, pp. 53-71.

PULIDO FERNÁNDEZ, J. (2011): «La sostenibilidad del modelo turístico español en un escenario de cambio global», Papeles de Economía Española, n 128 , pp. 38-52.

REBOLLO, A. (2001): «Almuñécar», en La actividad turística española en 2000, Castellón de la Plana, AECIT, pp. 513-518.

REINERT, M. (1993): «Les mondes lexicaux et leur logique á travers l'analyse statisque d'un corpus récints de cauchemars» Langage et Socíete, no 66, pp. 5-39.

REQUEJO LIBERAL, J. (2008): «¿Por qué lo llaman turismo cuando quieren decir promoción inmobiliaria?», en Destinos turísticos: viejos problemas ¿nuevas soluciones? $X$ Coloquio de Geografía del Turismo, Ocio y Recreación (A.G.E.), Cuenca, pp. 653-662.

RODRÍGUEZ GONZÁLEZ, P. (2007): Los andaluces y el turismo. Percepción social del turismo. Sevilla. Junta de Andalucía. 232 págs.

ROMÁN MÁRQUEZ, A. (2011). «Planes de dinamización y excelencia turística versus municipios turísticos: problemáticas, similitudes y diferencias esenciales», Papers de Turisme, $\mathrm{n}^{\circ}$ 49-50, pp. 25-43.

SÁNCHEZ ESCOLANO, L.M. (2011): «Gobernanza, planificación subregional y expansión urbanística. El caso del litoral de Granada», en Geografía y desafíos territoriales en el siglo XXI. Vol.2. Urbanismo Expansivo: de la utopía a la realidad. Universidad de Alicante, AGE. Alicante. pp. 665-676.

SÁNCHEZ ESCOLANO, L.M. y ESPINOSA ARIAS, J.A. (2012): «El binomio agricultura-turismo y su incidencia en el modelo territorial de la costa de Granada», Estudios Geográficos, no 55-56, pp. 189-203.

SANTOS PAVÓN, E. y FERNÁNDEZ TABALES, A. (2010): «El litoral turístico español en la encrucijada: entre la renovación y el continuismo», Cuadernos de Turismo, $\mathrm{n}^{\mathrm{o}} 25$, pp. 185-206.

SISTEMA DE INFORMACIÓN MULTITERRITOIAL DE ANDALUCÍA, (SIMA), 2001: Viviendas clasificadas por tipo. Instituto de Estadística de Andalucía, Junta de Andalucía.

SISTEMA DE INFORMACIÓN MULTITERRITOIAL DE ANDALUCÍA, (SIMA), 2010: Plazas en establecimientos hoteleros por clase. Instituto de Estadística de Andalucía, Junta de Andalucía. 
VERA REBOLLO, F. DÍEZ SANTO, D. e IVARS BIDAL, J. (2009): «El turismo de interior en la Comunitat Valenciana: La percepción desde las entidades municipales y asociaciones turísticas», Serie Geográfica, ${ }^{\circ}$ 15, pp. 27-38.

VERA REBOLLO, F., LÓPEZ PALOMEQUE, F., MARCHENA, M. y ANTON CLAVÉ, S. (2011): Análisis territorial del turismo y planificación de destinos turísticos. Valencia, Tirant lo Blanch, pp. 473. 
